\title{
Concomitant Chemoradiation in Locally Advanced Laryngeal Cancer
}

\author{
${ }^{1}$ Arif Jamshed, ${ }^{2}$ Raza Hussain, ${ }^{3}$ Sarah Jamshed, ${ }^{2}$ Aamir Ali Syed, ${ }^{4}$ Asif Loya, ${ }^{5}$ Mazhar Ali Shah \\ ${ }^{5}$ Uzma Majeed, ${ }^{5}$ Shahid Hameed \\ ${ }^{1}$ Department of Radiation Oncology, Shaukat Khanum Memorial Hospital and Research Center, Lahore, Pakistan \\ ${ }^{2}$ Department of Surgery, Shaukat Khanum Memorial Hospital and Research Center, Lahore, Pakistan \\ ${ }^{3}$ Medical Student, Aga Khan Medical University, Karachi, Pakistan \\ ${ }^{4}$ Department of Pathology, Shaukat Khanum Memorial Hospital and Research Center, Lahore, Pakistan \\ ${ }^{5}$ Department of Radiation Oncology, Shaukat Khanum Memorial Hospital and Research Center, Lahore, Pakistan
}

Correspondence: Arif Jamshed, Department of Radiation Oncology, Shaukat Khanum Memorial Hospital, Johar Town, Lahore Pakistan, Phone: 0092-300-4436985, e-mail: arifj@skm.org.pk

\begin{abstract}
Introduction: Despite the acceptance of concomitant chemoradiation (CRT) as an alternative to total laryngectomy (TL) in locally advanced laryngeal cancer (LALC), laryngeal preservation is sparingly recommended in developing countries. We report on prognostic factors and survival in T3/T4 laryngeal cancer treated with concomitant CRT at Shaukat Khanum Memorial Cancer Hospital and Research Center (SKMCH and $\mathrm{RC}$ ) to provide comparison with other geographic locations.

Material and Methods: During the period November 2003-April 2009, 101 patients with biopsy proven untreated LALC underwent concurrent CRT treatment at SKMCH and RC. According to AJCC staging system (6th edition) 41 had T3 and 60 patients had T4 disease. Radiation dose to the larynx was 70 Gy in 35 fractions with concomitant cisplatin. Induction chemotherapy was given to 42 patients. Thirty-one patients required tracheotomy either before or during concomitant CRT.

Results: Actuarial overall survival and laryngectomy free survival (LFS) for the whole group at 5 years were $54 \%$ (95\% Cl; 48-60) and 47\% $(95 \% \mathrm{Cl} ; 42-52)$ respectively. Median LFS was 4.17 years. On univariate analysis patients with T4 tumors $(p=0.04)$, positive neck nodal disease $(p=0.02)$, supraglottic site $(p=0.02)$ and tracheotomy $(0.009)$ had a significantly inferior LFS. Multivariate analysis showed tracheotomy to be the only factor significantly $(p=0.03)$ related to a higher risk of failure for LFS.

Conclusion: Survival rates for LALC treated with concomitant CRT in our institution are acceptable. Our study supports the use of TL in patients with compromised airways that require tracheotomy as outcome with concomitant CRT is poor.
\end{abstract}

Keywords: Carcinoma larynx, Chemoradiation, Laryngeal preservation.

\section{INTRODUCTION}

Worldwide estimates predict over 160,000 new cases of laryngeal cancer in males and 22,000 cases among females. These predictions account for $1.7 \%$ of all new cancer cases around the world. Men are more commonly affected than females. The male/female ratio of almost 7:1 in laryngeal cancer is higher than for cancer at any other site. ${ }^{1}$ Pakistan falls into a high risk head and neck cancer geographical zone. Data from the population-based cancer registry in Karachi shows head and neck malignancies to account for approximately $21 \%$ of the cancers in males and about $11 \%$ in females. The age standardized incidence rate of 8.6 per 100,000 in Karachi for laryngeal cancer is among the highest in Asia and it constitutes 5.0\% of all cancers in men. ${ }^{2}$ Over
95\% of laryngeal cancers are of squamous cell histology and the relationship with cigarette smoking is well established. ${ }^{3}$ Carcinoma of the vocal cords is the most common form of laryngeal cancer followed by supraglottic cancer. Subglottic carcinomas are rare and account for less than $2 \%$ of all laryngeal cancers. ${ }^{4}$

Early laryngeal cancer has a high cure rate with either radiation or voice preserving modern surgical techniques. ${ }^{5}$ The treatment of locally advanced disease has gradually evolved from radical surgery as the mainstay to larynx preserving therapies as the principle treatment. The treatment strategies available to preserve the larynx include conservative laryngeal surgery, radiation alone, induction chemotherapy followed by radiation and concomitant chemoradiation (CRT) ${ }^{6}$ Laryngeal preservation is sparingly 
recommended in developing countries and total laryngectomy (TL) continues as the most widely practiced treatment in locally advanced disease. We report on prognostic factors and survival in locally advanced laryngeal cancer treated with concomitant CRT at Shaukat Khanum Memorial Cancer Hospital and Research Center (SKMCH \& RC) to provide comparison with other geographic locations.

\section{PATIENTS AND METHODS}

Our institutional policy is to recommend concomitant CRT in all cases with locally advanced laryngeal cancer except those with compromised airways or extensive cartilage involvement. Patients who refuse primary laryngectomy are also treated with concomitant CRT. The head and neck unit prospective database at SKMCH \& RC collects data on all patients with head and neck malignancies. The database identified 122 patients with locally advanced laryngeal cancer treated with primary radical radiotherapy between November 2003 and April 2009. Twenty-one patients who received radiotherapy without concomitant chemotherapy were excluded. This series covers the remaining 101 patients with biopsy proven locally advanced laryngeal squamous cell carcinoma treated with concomitant CRT. Primary disease was assessed by a comprehensive clinical examination of the head and neck and fiberoptic nasendoscopy. Tumors were staged according to the AJCC 6th edition (American Joint Commission on Cancer). A computed tomographic scan or magnetic resonance imaging scan of the head and neck and chest radiograph were obtained.

\section{Treatment}

Patients were simulated and treated in a beam directed shell with conventional planning. Radiation therapy was given with either a cobalt-60 unit or a $6 \mathrm{MV}$ linear accelerator. Large opposing lateral portals were used to treat the primary tumor and upper neck at 2.0 Gy per fraction, once a day, 5 days a week to a total dose of $70 \mathrm{~Gy}$ in 35 fractions in 7 weeks. The spinal cord was excluded after $45 \mathrm{~Gy}$ from the lateral portals through shrinking field technique with customized blocks. The anterior neck field was treated at 2 Gy per fraction 5 fractions per week to a dose of 45-50 Gy in 25 fractions over, 5 weeks. Tracheotomy was performed in patients with compromised airways and tracheal stoma was boosted to 60-66 Gy. Tissue compensators were used as appropriate to enhance radiation dose homogeneity. Beam verification films were obtained for each field at the start of treatment and then at weekly intervals. Percutaneous endoscopic gastrostomy (PEG) was recommended in all cases.

Concurrent chemotherapy with cisplatin was administered either as a three weekly schedule $\left(75 \mathrm{mg} / \mathrm{m}^{2}\right.$ day 1, 22 and 43) or as weekly $\left(30 \mathrm{mg} / \mathrm{m}^{2}\right)$ treatment. Patients received prophylactic hydration and antiemetics. Induction chemotherapy when used was either with gemcitabine cisplatin (GC) or cisplatin 5-fluorouracil. GC, according to the institutional protocol, was given as cisplatin $75 \mathrm{mg} / \mathrm{m}^{2}$ and administered by a 60 -minute infusion of $5 \%$ glucose in normal saline on day 1 . Gemcitabine 1,000 $\mathrm{mg} / \mathrm{m}^{2}$ intravenously over 30 minutes on day 1 and 8 of each 21-day cycle.

\section{Assessment of Response}

Response to concomitant CRT was assessed during 6-8 weeks after the completion of therapy by examination of the head and neck and fiberoptic nasendoscopy. Complete response was defined as disappearance of all disease. Thereafter, patients were followed up at 3 monthly intervals. Patients with suspected persistent or recurrent disease were restaged with MRI neck and biopsy.

\section{Statistical Analysis}

Statistical Package for Social Sciences, version 10, was used to run statistical analysis. Survival analyses were carried out through univariate and multivariate methods. The former was primarily used to screen through the potential prognostic factors searching for any, that was significantly related to survival. The log rank test was used to measure the significance. Cox Proportional Hazards Model was applied to test if the variables significantly associated with survival in the Kaplan Meier analysis were also significantly associated with the variables in the multivariate survival analysis by determining the probability of end point called the hazard. Probability of entry into the model was set at 0.10 and of removal at 0.20 and backward logistic regression method was constructed to see which variables were significantly associated with survival. The level of significance for the factors analysed with the multivariate survival analysis were calculated by the likelihood ratio test. For overall survival (OS) and laryngectomy free survival (LFS), the duration was calculated from the date of start of 
treatment to the time of event. Patients terminally ill at last follow-up are considered dead. Deaths and losses to followup were considered as events for overall OS and LFS. All patients not obtaining a complete response in 6-8 weeks following completion of CRT represent events for LFS. Data was evaluated in March 2010.

\section{RESULTS}

Patient characteristics are shown in Table 1 . The median age of the group was 55 years ranging from 22 to 75 years. Twentyseven patients were $\leq 50$ years of age. Concomitant cisplatin was given 3 weekly in 85, weekly in 12 and in combination with 5-FU in 4 patients. Forty-two patients received induction chemotherapy; GC in 38 and CF in 4 patients. Fifty-three percent (32/60) with T4 and 24\% (10/41) of patients with T3 disease were treated with induction chemotherapy. Concomitant CRT was completed in $\leq 50$ days in $46 \%$ and $>50$ days in $54 \%$ of the patients. Tracheotomy was performed in 31 patients either before or during treatment. Eighty-three patients had a PEG tube placed before the commencement of CRT.

Table 1: Characteristics of patients

\begin{tabular}{|c|c|}
\hline Characteristics & $(N=101)$ \\
\hline $\begin{array}{l}\text { Age-years } \\
\text { Median } \\
\text { Range }\end{array}$ & $\begin{array}{r}55 \\
22-75\end{array}$ \\
\hline $\begin{array}{l}\text { Sex-no. } \\
\text { Males } \\
\text { Females }\end{array}$ & $\begin{array}{l}90 \\
11\end{array}$ \\
\hline $\begin{array}{l}\text { Performance status-no. } \\
\text { ECOG 1-2 }\end{array}$ & 101 \\
\hline $\begin{array}{l}\text { Site of tumor-no. } \\
\text { Supraglottis } \\
\text { Glottic }\end{array}$ & $\begin{array}{l}22 \\
79\end{array}$ \\
\hline $\begin{array}{l}\text { AJCC Stage-no. } \\
\text { III } \\
\text { IV }\end{array}$ & $\begin{array}{l}40 \\
61\end{array}$ \\
\hline $\begin{array}{l}\text { Tumour stage-no. } \\
\text { T3 } \\
\text { T4 }\end{array}$ & $\begin{array}{l}40 \\
61\end{array}$ \\
\hline $\begin{array}{l}\text { Node stage-no. } \\
\text { N0 } \\
\text { N1 }\end{array}$ & $\begin{array}{l}87 \\
14\end{array}$ \\
\hline $\begin{array}{l}\text { Histology-no. } \\
\text { Squamous cell carcinoma }\end{array}$ & 101 \\
\hline $\begin{array}{l}\text { Grade-no. } \\
\text { Well } \\
\text { Moderate } \\
\text { Poor } \\
\text { Unknown }\end{array}$ & $\begin{array}{r}36 \\
44 \\
6 \\
15\end{array}$ \\
\hline
\end{tabular}

\section{Response}

In March 2010, 61 patients were alive, 4 patients were alive with disease and 36 patients were either known to be dead or terminal when last seen. Only one patient died of unrelated causes. Overall 45 patients failed treatment. In 26 of these patients persistent local disease was present at first followup following completion of CRT and a further 19 patients failed after achieving a complete response. The site of relapse following complete remission was local/locoregional in 16 and distant metastases in 3 patients. For a substantial number of failures, no curative salvage treatment could be given. Fifteen patients refused salvage laryngectomy, 11 patients were not amenable to salvage laryngectomy either due to advanced local/locoregional disease (8 patients) or distant metastases ( 3 patients) and further 3 patients were judged medically unfit for surgery. Salvage laryngectomy was performed in 16 patients for persistent or recurrent local disease. Surgery salvaged 6 patients successfully and they remain free of disease in $3,12,16,23,26$, and 30 months after laryngectomy.

\section{Survival}

Follow-up ranged from 2 to 78 months (median 24 months). Actuarial OS and LFS for the whole group of 101 patients at 5 years were $54 \%$ (95\% CI; 48-60) and 47\% (95\% CI; 42-52) respectively (Figs 1 and 2). Median LFS was 4.17 years. Actuarial OS and LFS rates at 5 years according to clinical, pathological and therapeutic variables are presented in Table 2. Patients with T4 tumors (Fig. 3), positive neck nodal disease (Fig. 4), supraglottic site (Fig. 5) and tracheotomy (Fig. 6) had a significantly inferior LFS. Age $(p=0.28)$, sex $(p=0.72)$, smoking $(p=0.46)$, histological grade $(p=0.23)$, radiation treatment time $(p=0.33)$ and induction chemotherapy $(\mathrm{p}=0.82)$ did not significantly influence LFS. Multivariate analysis showed that tracheotomy was independently and significantly $(p=0.03)$ related to a higher risk of failure for LFS.

\section{DISCUSSION}

The current treatment trend in advanced laryngeal cancer is towards the avoidance of radical surgery whenever possible. Induction chemotherapy followed by radiotherapy as organ preserving treatment gained acceptance in 1990s following Veterans Affairs Laryngeal Cancer Study Group trial. The larynx was preserved in 64 percent in the nonsurgical arm, 


\begin{tabular}{|c|c|c|c|c|}
\hline Group & OS $(95 \% \mathrm{Cl})$ & $P$ value & LFS $(95 \% \mathrm{Cl})$ & $P$ value \\
\hline All (101) & $54(48-60)$ & & $47(42-52)$ & \\
\hline $\begin{array}{l}\text { Age } \\
<50(27) \\
>50(74)\end{array}$ & $\begin{array}{l}63(52-74) \\
51(44-58)\end{array}$ & 0.33 & $\begin{array}{l}57(46-68) \\
45(39-51)\end{array}$ & 0.28 \\
\hline $\begin{array}{l}\text { Sex } \\
\text { Males (90) } \\
\text { Females (11) }\end{array}$ & $\begin{array}{l}58(53-63) \\
40(20-60)\end{array}$ & 0.96 & $\begin{array}{l}49(44-54) \\
44(23-65)\end{array}$ & 0.72 \\
\hline $\begin{array}{l}\text { Laryngeal site } \\
\text { Supraglottis (22) } \\
\text { Glottis (79) }\end{array}$ & $\begin{array}{l}29(19-39) \\
65(59-71)\end{array}$ & 0.0016 & $\begin{array}{l}28(18-38) \\
55(49-61)\end{array}$ & 0.02 \\
\hline $\begin{array}{l}T \text { stage } \\
\text { T3 (41) } \\
\text { T4 (60) }\end{array}$ & $\begin{array}{l}63(52-74) \\
49(42-56)\end{array}$ & 0.09 & $\begin{array}{l}56(46-66) \\
42(36-48)\end{array}$ & 0.04 \\
\hline $\begin{array}{l}N \text { stage } \\
\text { No (87) } \\
\mathrm{N}+(14)\end{array}$ & $\begin{array}{l}58(51-65) \\
30(16-44)\end{array}$ & 0.05 & $\begin{array}{l}51(45-57) \\
27(14-40)\end{array}$ & 0.02 \\
\hline $\begin{array}{l}\text { Grade } \\
\text { Well (36) } \\
\text { Moderate (44) } \\
\text { Poor (6) } \\
\text { Unknown (15) }\end{array}$ & $\begin{array}{l}70(61-79) \\
40(30-50) \\
67(48-86) \\
55(43-68)\end{array}$ & 0.14 & $\begin{array}{l}55(46-64) \\
38(29-47) \\
66(47-85) \\
48(34-62)\end{array}$ & 0.40 \\
\hline $\begin{array}{l}\text { CRT treatment time } \\
<7 \text { weeks }(47) \\
>7 \text { weeks }(54)\end{array}$ & $\begin{array}{l}66(58-74) \\
46(38-54)\end{array}$ & 0.11 & $\begin{array}{l}54(46-62) \\
43(36-50)\end{array}$ & 0.33 \\
\hline $\begin{array}{l}\text { Tracheotomy } \\
\text { No }(70) \\
\text { Yes }(31)\end{array}$ & $\begin{array}{l}61(52-70) \\
33(23-43)\end{array}$ & 0.02 & $\begin{array}{l}55(48-62) \\
28(20-36)\end{array}$ & 0.009 \\
\hline $\begin{array}{l}\text { Induction chemotherapy } \\
\text { No (60) } \\
\text { Yes (41) }\end{array}$ & $\begin{array}{l}55(48-62) \\
54(45-63)\end{array}$ & 0.84 & $\begin{array}{l}51(58-65) \\
41(32-50)\end{array}$ & 0.82 \\
\hline
\end{tabular}

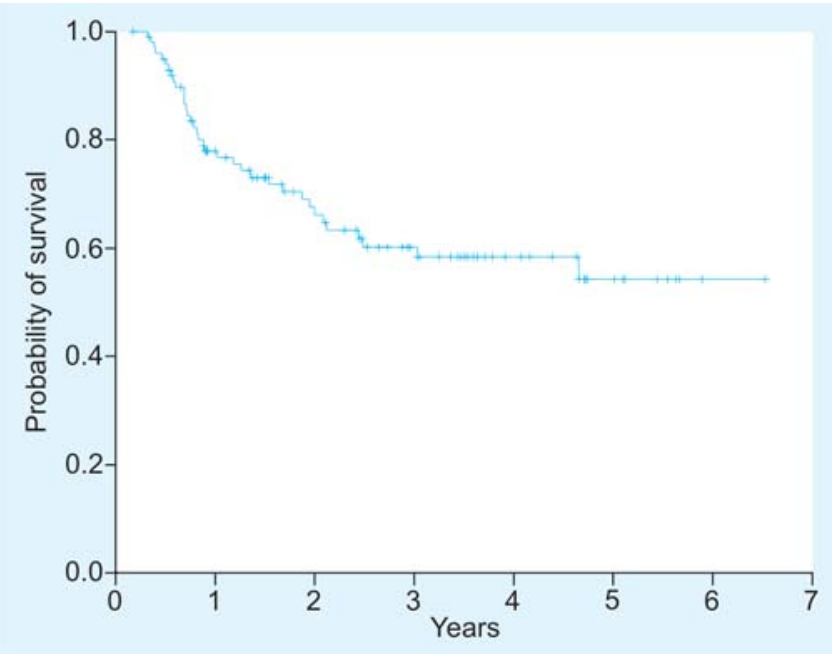

Number at risk

\begin{tabular}{|l|l|l|l|l|l|l|}
\hline 101 & 67 & 49 & 32 & 19 & 10 & 1 \\
\hline
\end{tabular}

Fig. 1: Overall survival (OS)

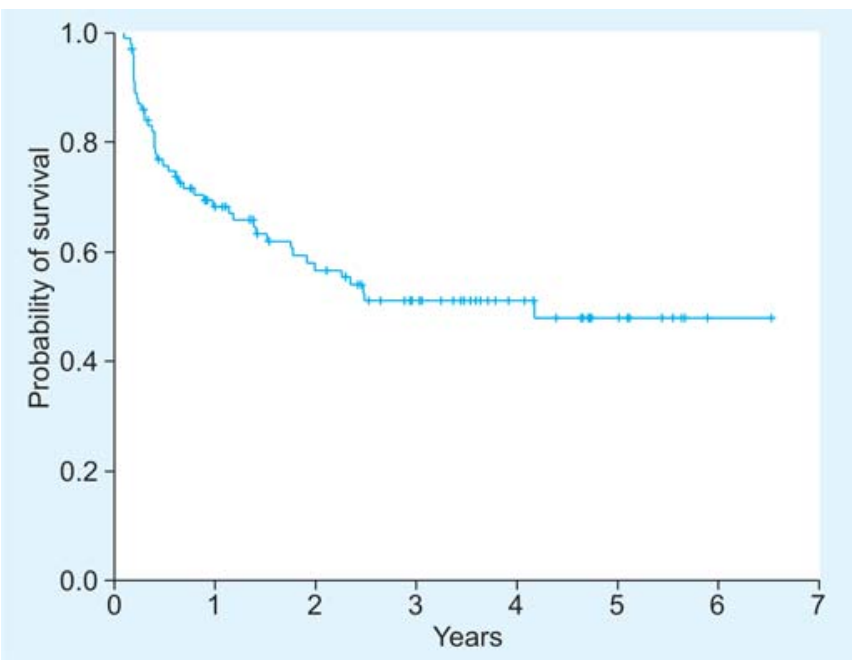

Number at risk

\begin{tabular}{|l|l|l|l|l|l|l|}
\hline 101 & 59 & 43 & 31 & 18 & 10 & 1 \\
\hline
\end{tabular}

Fig. 2: Laryngectomy free survival (LFS) 


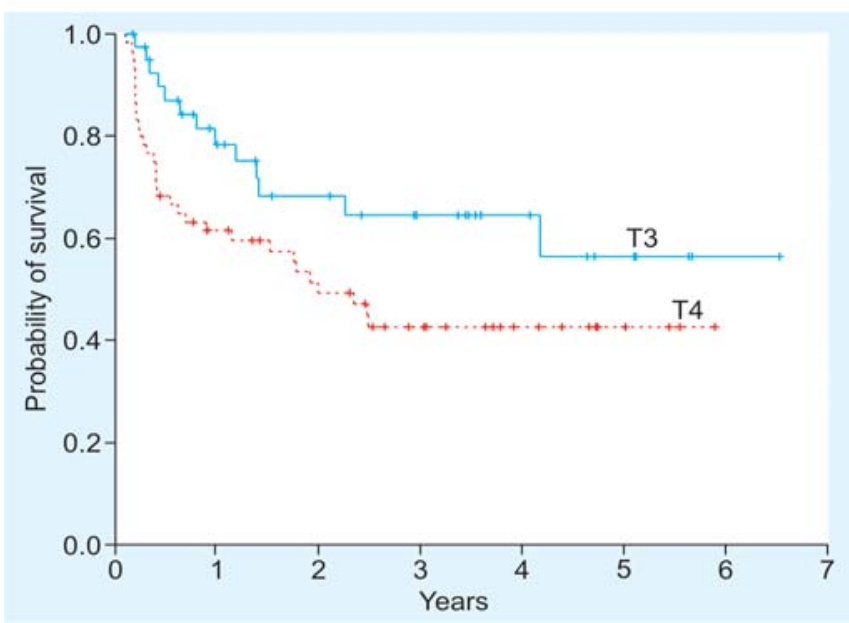

Number at risk

\begin{tabular}{|l|l|l|l|l|l|l|l|}
\hline T3 & 41 & 26 & 19 & 14 & 9 & 5 & 1 \\
\hline T4 & 60 & 33 & 24 & 16 & 9 & 4 & 0 \\
\hline
\end{tabular}

Fig. 3: LFS by T stage

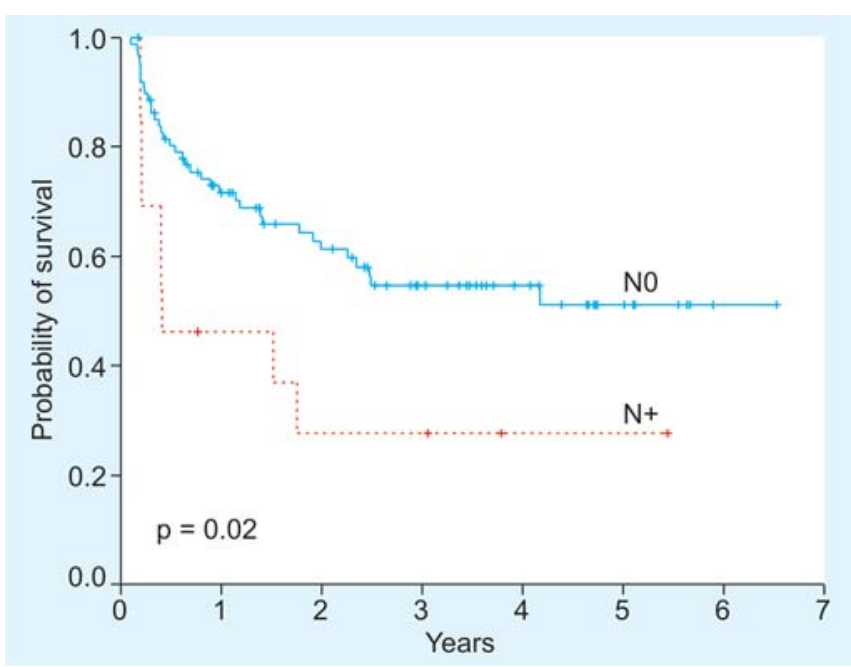

Number at risk

\begin{tabular}{|l|l|l|l|l|l|l|l|}
\hline $\mathrm{N} 0$ & 87 & 54 & 40 & 27 & 17 & 8 & 1 \\
\hline $\mathrm{N}+$ & 14 & 5 & 3 & 3 & 2 & 1 & 0 \\
\hline
\end{tabular}

Fig. 4: LFS by $\mathrm{N}$ stage

and the two-year survival rate was 68 percent in both groups. ${ }^{7}$ The ability to preserve the larynx without compromising survival established the use of induction chemotherapy followed by radiotherapy as a nonsurgical option for patients with advanced laryngeal cancer. In the European Organization for Research and Treatment of Cancer (EORTC) Hypopharynx Trial, functional larynx was

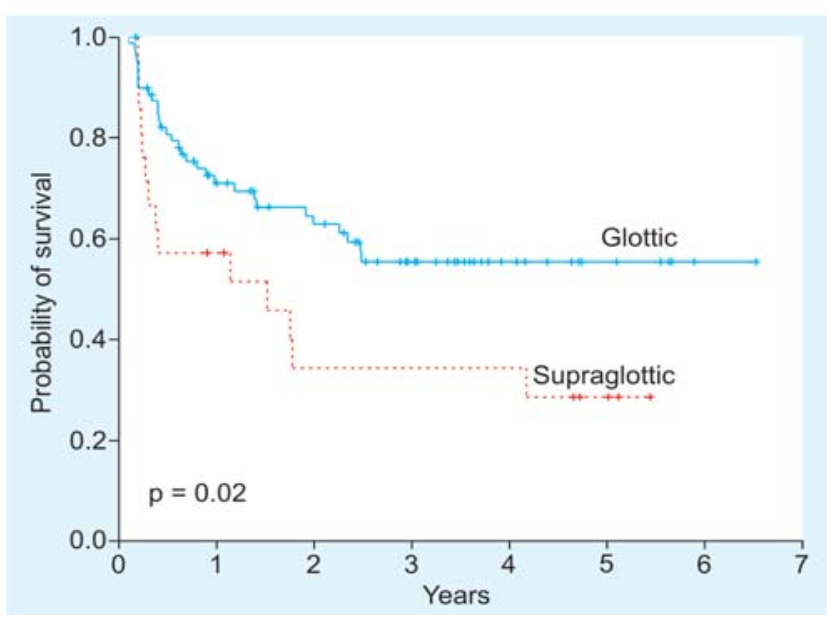

Number at risk

\begin{tabular}{|l|c|c|c|c|c|c|c|}
\hline Glottic & 87 & 54 & 40 & 27 & 17 & 8 & 1 \\
\hline Supraglottic & 14 & 5 & 3 & 3 & 2 & 1 & 0 \\
\hline
\end{tabular}

Fig. 5: LFS by laryngeal subsite

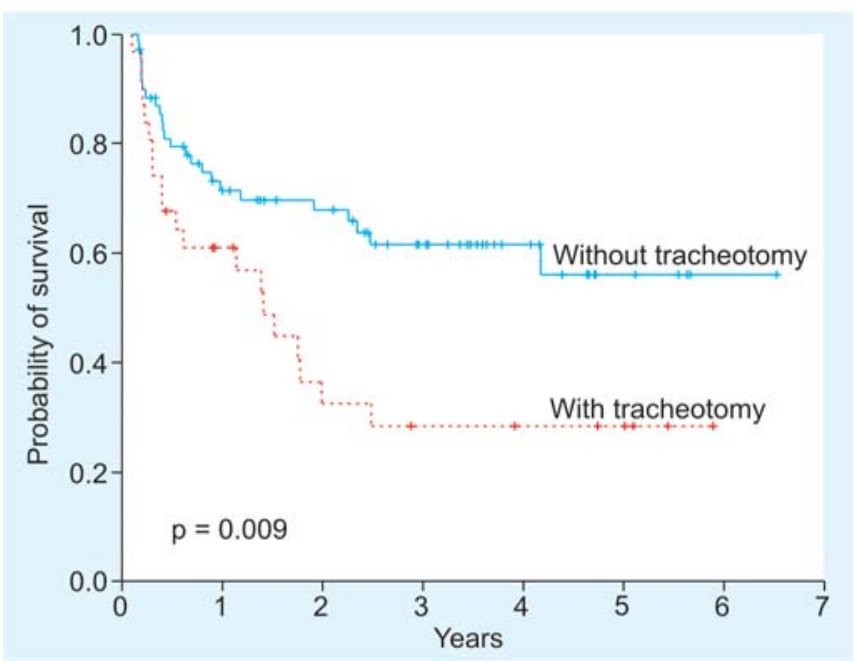

Number at risk

\begin{tabular}{|l|c|c|c|c|c|c|c|}
\hline With tracheotomy & 31 & 16 & 8 & 6 & 5 & 4 & 0 \\
\hline Without tracheotomy & 70 & 43 & 35 & 24 & 13 & 5 & 1 \\
\hline
\end{tabular}

Fig. 6: LFS by tracheotomy

retained in approximately half of the long-term survivors in the CRT arm. ${ }^{8}$ The Radiation Therapy Oncology Group and the Head and Neck Inter. Group conducted a randomized trial (RTOG 91-11) to investigate the contributions of chemotherapy and radiotherapy to larynx-preserving treatment. The three arm study compared induction chemotherapy followed by radiotherapy, concurrent CRT 
with and radiotherapy alone. The primary objective of the trial was to compare the rates of laryngeal preservation associated with three treatments. Patients with T1 disease or high-volume T4 disease (defined as more than $1 \mathrm{~cm}$ of invasion of the base of the tongue or tumor penetration of thyroid cartilage into soft tissues) were excluded. In two years, the proportion of patients who had an intact larynx after radiotherapy with concurrent cisplatin (88\%) differed significantly from the proportions in the groups given induction chemotherapy followed by radiotherapy (75\%, $\mathrm{P}=0.005)$ or radiotherapy alone $(70 \%, \mathrm{P}<0.001)$. Grade 3 to 4 mucosal toxicity was twice as frequent with concurrent treatment as with other two arms. There was no difference in late toxicity among the three arms. On the basis of these findings, radiotherapy with concomitant administration of cisplatin emerged as the new standard for CRT treatment. ${ }^{9}$

A meta-analysis of induction chemotherapy and definite radiation trials in laryngeal preservation showed a laryngeal preservation rate among survivors to be $58 \%$ and that survival was not compromised by function sparing approach. It was unclear whether induction chemotherapy had an independent therapeutic effect or allowed for the selection of patients suitable for laryngeal preservation with radiation. ${ }^{10}$

Gemcitabine and cisplatin are both drugs with proven clinical activity in a variety of solid tumors, have no overlapping toxic side-effects and are different with respect to cellular metabolism. In combination with cisplatin, the regime has a documented favorable toxicity profile in randomized trials for lung and bladder cancer. ${ }^{11,12}$ The standard CF regime yields a $15-30 \%$ overall response rate and 4-6 month survival in advanced or recurrent head and neck cancer. ${ }^{13,14}$ In the EORTC trial for patients with advanced head and neck cancer, single agent gemcitabine produced a $13 \%$ response rate with mild toxicity. ${ }^{15}$ In combination with cisplatin, a $23 \%$ overall response rate was observed in advanced or recurrent head and neck cancer. ${ }^{16}$ In our institution, GC combination is used in untreated locally advanced head and neck cancer patients as an ambulatory outpatient schedule due to its low toxicity and comparable response rates. In our series induction, chemotherapy was predominantly used in patients with more advanced disease. While there was no significant difference in survival among patients treated with or without induction, chemotherapy, the group treated without chemotherapy had a relatively improved outcome. This observation is likely due to lower stage disease treated with no induction chemotherapy.
There are no reliable predictors of outcomes for larynx preservation treatment. However, patients with extensive cartilage invasion, tongue base involvement, compromised airways and supraglottic subsite are considered poor candidates for a function sparing approach. ${ }^{9,17}$ The LFS for the whole group at 5 years in our series was $47 \%$. These results are marginally inferior to laryngeal preservation rates of CRT treatment arms of large randomized trials. ${ }^{7-9}$ The lower LFS in this series is likely to be due to a higher proportion of high risk patients treated with CRT. Over $20 \%$ of the patients had supraglottic subsite and $60 \%$ had T4 disease. The 5 year LFS for supraglottic and glottic carcinomas was $29 \%$ and $65 \%$ respectively $(p=0.001)$. On univariate analysis, the survival of these patients was significantly inferior to T3 tumors ( $56 \%$ vs $42 \%, \mathrm{p}=0.04$ ). Several studies have shown poor outcome of patients with tracheotomy. ${ }^{18}$ The dismal survival of patients with tracheotomy in this series is consistent with literature and tracheotomy emerged as the only independent prognostic factor significantly associated with poor LFS on multivariate analysis.

The potential risk of prolongation of radiotherapy treatment time in head and neck is well documented. ${ }^{19}$ Prolonged overall radiotherapy treatment time has a major effect on locoregional control and survival. In this series, overall treatment time showed a trend towards improved LFS survival with radiotherapy treatment $>50$ days was $43 \%$ in contrast to $54 \%$ in patients with radiotherapy treatment time of $\leq 50$ days. Treatment related toxicity accounted for unscheduled radiation treatment interruption in only a few cases. In the majority of patients, gaps in radiation treatment were not related to treatment toxicity. Patients undergoing treatment at SKMCH \& RC travel from all over the country involved long road and rail journeys. Family commitments, commuting, extreme weather and machine breakdown are some of the factors causing prolonged radiotherapy treatment time in this region.

Salvage among local failures in our series was disappointing. The unsatisfactory salvage rates can be attributed either to advanced locoregional disease or treatment biased by patients leading to refusal of curative surgery. There is no data in developing countries on refusal rate for total laryngectomy but the number is likely to be high due to illiteracy and and low levels of health awareness. Patients often seek traditional or alternative therapies over surgical treatment that inevitably leads to delay and progression rendering initially operable disease inoperable. 
Laryngectomy is among the most mutilating and feared treatments of cancer. The loss of voice, altered swallowing, and a permanent tracheotomy, continue to affect the patients' quality of life (QOL), both in terms of physical and psychological status. ${ }^{20-22}$ In developed countries, most patients undergo voice rehabilitation following laryngectomy however, a significant proportion are disappointed with results of voice restoration. ${ }^{23}$ Improved voice rehabilitation following TL in particular with tracheoesophageal (TE) voice restoration has changed the situation as it provides a good functional outcome and better QOL. ${ }^{24}$ The availability of voice restoration options in developing countries is limited and remains inaccessible for larger population. The average family annual income in South Asia is less than the retail price of a good artificial larynx; and the cost of TE puncture prostheses makes voice restoration with these devices unfeasible for the overwhelming majority of cases. The morbidity of TL is compounded in these countries where loss of speech in a predominantly illiterate patient population who are unable to write has an even more devastating impact on their QOL. The likelihood of laryngectomies being forced into an isolated life as a mute and dysphasic recluse may explain the observed high refusal rate for laryngectomy in our population. ${ }^{24}$

In summary, our survival rates for locally advanced laryngeal cancer treated with concomitant CRT are acceptable and discussion on laryngeal preservation should form a part of the consultative process in developing countries. In patients requiring tracheotomy for compromised airways, our study supports the use of TL as outcome with CRT is poor. The high refusal rate for both primary and salvage TL is of concern; there is need to expand voice rehabilitation, counselling and support services in the developing world to increase acceptance of TL as a therapeutic procedure.

\section{REFERENCES}

1. Ferlay J, Bray F, Pisani P, Parkin DM. Globocan 2000: Cancer incidence, mortality and prevalence worldwide. Version 1. Cancer base No. 5. Lyon: IARC Press; 2001.

2. Bhurgri Y, Bhurgri A, Usman A, et al. Epidemiological review of head and neck cancers in Karachi. Asian Pac J Cancer Prev 2006 Apr-Jun;7(2):195-200.

3. Spitz MR. Epidemiology and risk factors for head and neck cancer. Semin Oncol 1994;21(3):281-88.

4. Garas J, McGuirt WF Sr. Squamous cell carcinoma of the subglottis. Am J Otolaryngol 2006 Jan-Feb;27(1):1-4.

5. Jones AS, Fish B, Fenton JE, Husband DJ. The treatment of early laryngeal cancers (T1-T2 N0): surgery or irradiation? Head Neck 2004 Feb;26(2):127-35.
6. American Society of Clinical Oncology, Pfister DG, Laurie SA, Weinstein GS, et al. American Society of Clinical Oncology clinical practice guideline for the use of larynx-preservation strategies in the treatment of laryngeal cancer. J Clin Oncol 2006 Aug 1;24(22):3693-704.

7. The Department of Veterans Affairs Laryngeal Cancer Study Group. Induction chemotherapy plus radiation compared with surgery plus radiation in patients with advanced laryngeal cancer. N Engl J Med 1991;324:1685-90.

8. Lefebvre JL, Chevalier D, Luboinski B, et al. Larynx preservation in pyriform sinus cancer: Preliminary results of a European Organization for Research and Treatment of Cancer phase III trial. EORTC Head and Neck Cancer Cooperative Group. J Natl Cancer Inst 1996;88:890-99.

9. Forastiere AA, Goepfert H, Maor M, et al. Concurrent chemotherapy and radiotherapy for organ preservation in advanced laryngeal cancer. N Engl J Med 2003;349:2091-98.

10. Pignon JP, Bourhis J, Domenge C, et al. Chemotherapy added to locoregional treatment for head and neck squamous-cell carcinoma: Three meta-analyses of updated individual data. MACH-NC Collaborative Group. Meta-Analysis of Chemotherapy on Head and Neck Cancer. Lancet 2000;355: 949-55.

11. L Crino, G Scagliotti, M Marangolo. Cisplatin-gemcitabine combination in advanced non-small-cell lung cancer: A phase II study. J Clin Oncol 1997;15:297-303.

12. H von der Maase, L Sengelov, JT Roberts. Long-term survival results of a randomized trial comparing gemcitabine plus cisplatin, with methotrexate, vinblastine, doxorubicin, plus cisplatin in patients with bladder cancer. J Clin Oncol 2005;23:4602-08.

13. Jacobs C, Lyman G, Velez-Garcia E, et al. A phase III randomized study comparing cisplatin and fluorouracil as single agents and in combination for advanced squamous cell carcinoma of the head and neck. J Clin Oncol 1992;10:257-63.

14. Clavel M, Vermorken JB, Cognetti F, et al. Randomized comparison of cisplatin, methotrexate, bleomycin and vincristine (CABO) versus cisplatin and 5-fluorouracil (CF) versus cisplatin (C) in recurrent or metastatic squamous cell carcinoma of the head and neck. A phase III study of the EORTC Head and Neck Cancer Cooperative Group. Ann Oncol 1994;5:521-26.

15. Catimel G, Vermorken JB, Clavel M, de Mulder P, Judson I, Sessa C, Piccart M, Bruntsch U, Verweij J, Wanders J. A phase II study of gemcitabine (LY 188011) in patients with advanced squamous cell carcinoma of the head and neck. EORTC Early Clinical Trials Group. Ann Oncol 1994 Jul;5(6):543-47.

16. R Hitt, D Castellano, M Hidalgo. Phase II trial of cisplatin and gemcitabine in advanced squamous-cell carcinoma of the head and neck. Ann Oncol 1998;9:1347-49.

17. Nicolai P, Redaelli de Zinis LO, Tomenzoli D, et al. Prognostic determinants in supraglottic carcinoma: Univariate and Cox regression analysis. Head Neck Jul 1997;19(4):323-34.

18. Carrillo JF, Frias-Mendivil M, Lopez-Graniel C, et al. The impact of preoperative tracheotomy on T3 transglottic carcinomas of the larynx. Eur Arch Otorhinolaryngol 1999;256(2):78-82. 
19. Overgaard J, Alsner J, Eriksen J, et al. Importance of overall treatment time for the response to radiotherapy in patients with squamous cell carcinoma of the head and neck. Rays $2000 \mathrm{Jul}-$ Sep;25(3):313-19.

20. Lefebvre JL. Laryngeal preservation in head and neck cancer: Multidisciplinary approach. Lancet Oncol 2006;7:747-55.

21. Terrell JE, Fisher SG, Wolf GT: Long-term quality of life after treatment of laryngeal cancer. The Veterans Affairs Laryngeal Cancer Study Group. Arch Otolaryngol Head Neck Surg 1998;124:964-71.
22. Braz DS, Ribas MM, Dedivitis RA, et al. Quality of life and depression in patients undergoing total and partial laryngectomy. Clinics. 2005 Apr;60(2):135-42. Epub 2005 Apr 26.

23. Kazi R, Singh J, De Cordova J, et al. Postlaryngectomy Vocal Rehabilitation: Assessment Using a Validated Questionnaire in 51 Patients. ORL J Otorhinolaryngol Relat Spec 2007 Jun 12;69(5):289-94.

24. Elmiyeh B, Dwivedi RC, Jallali N, Chisholm EJ, Kazi R, Clarke PM, Rhys-Evans PH. Surgical voice restoration after total laryngectomy: An overview. Indian J Cancer 2010;47:239-47. 